\title{
Detection of new SHV-12, SHV-5 and SHV-2a variants of extended spectrum Beta-lactamase in Klebsiella pneumoniae in Egypt
}

\author{
Enas A Newire ${ }^{1 *}$, Salwa F Ahmed ${ }^{1}$, Brent House ${ }^{1}$, Esmeralda Valiente $^{2}$ and Guillermo Pimentel ${ }^{1}$
}

\begin{abstract}
Background: Klebsiella pneumoniae outbreaks possessing extended-spectrum $\beta$-lactamase- (ESBL) mediated resistance to third-generation cephalosporins have increased significantly in hospital and community settings worldwide. The study objective was to characterize prevalent genetic determinants of TEM, SHV and CTX-M types ESBL activity in K. pneumoniae isolates from Egypt.

Methods: Sixty five ESBL-producing K. pneumoniae strains, isolated from nosocomial and community-acquired infections from 10 Egyptian University hospitals (2000-2003), were confirmed with double disc-synergy method and E-test. blaTEM, blaSHV and blaCTX-m genes were identified by PCR and DNA sequencing. Pulsed-field gel electrophoresis (PFGE) was conducted for genotyping.

Results: All isolates displayed ceftazidime and cefotaxime resistance. blaTEM and blaSHV genes were detected in 98\% of the isolates' genomes, while $11 \%$ carried blaCTX-m. DNA sequencing revealed plasmid-borne SHV-12,-5,-2a (17\%), CTX-m-15 (11\%), and TEM-1 (10\%) prevalence. Among SHV-12 ( $n=8)$, one isolate displayed 100\% blaSHV-12 amino acid identity, while others had various point mutations: T17G (Leu to Arg, position 6 of the enzyme: $n=2$ ); A8T and A10G (Tyr and lle to Phe and Val, positions 3 and 4, respectively: $n=4$ ), and; A703G (Lys to Glu 235: $n=1$ ). SHV-5 and SHV-2a variants were identified in three isolates: T17G $(n=1) ; A 703 G$ and G705A (Ser and Lys to Gly and Glu: $n=1$ ); multiple mutations at A8T, A10G, T17G, A703G and G705A ( $n=1)$. Remarkably, 57\% of community-acquired isolates carried CTX-m-15. PFGE demonstrated four distinct genetic clusters, grouping strains of different genetic backgrounds.
\end{abstract}

Conclusions: This is the first study demonstrating the occurrence of SHV-12, SHV-5 and SHV-2a variants in Egypt, indicating the spread of class A ESBL in K. pneumoniae through different mechanisms.

\section{Background}

K. pneumoniae is a facultative anaerobic, Gram negative bacteria of the Enterobacteriaceae family, and a reported opportunistic pathogen that has been implicated in many community- and hospital-acquired infections [1]. This organism can initiate urinary tract infections, wound infections, pneumonia, intra-abdominal infections, nasal mucosa atrophy, and rhinoscleroma. The number of outbreaks involving $K$. pneumoniae strains with extended spectrum $\beta$-lactamase (ESBL) mediated resistance to

\footnotetext{
* Correspondence: enasnewire@hotmail.com

${ }^{1}$ Global Disease Detection and Response Program, U.S. Naval Medical

Research Unit No. 3 (NAMRU-3), Abbassia, Cairo, Egypt

Full list of author information is available at the end of the article
}

third-generation cephalosporins has been progressively increasing in many parts of the world [1].

$\beta$-lactamases, the precursors to ESBLs, confer resistance by inactivating $\beta$-lactam antibiotics [2], like penicillins, cephalosporins, carbapenems, and monobactams, by breaking open the four atom $\beta$-lactam ring structure. The extended spectrum $\beta$-lactamases (ESBLs) are a rapidly developing group of enzymes with the ability to hydrolyze third-generation cephalosporins as well as the monobactams and aztreonams that are known to be active against Klebsiella species. Clavulanic acid is a potent inhibitor of the $\beta$-lactamases and is commonly included with $\beta$-lactam antibiotics when an ESBL-producing bacterium is suspected. Clavulanic acid is a member of the clavams or oxapenams that inhibits $\beta$-lactamase activity by cova-

\section{Biomed Central}


lently binding to the serine that resides in the active site of the enzyme.

ESBL genes originally evolved from the $\beta$-lactamase TEM-1, TEM-2, and SHV-1 genes through mutations of the amino acids surrounding the active site $\beta$-lactamases.

ESBLs have recently become a significant problem because they are commonly plasmid-encoded, facilitating a high rate of horizontal transfer between different bacterial species [3]. Furthermore, such plasmids typically carry resistance genes to other drugs such as the aminoglycosides, thus narrowing treatment options.

As an illustration, administration of cephalosporins has recently been linked to increasing treatment failure rates, and isolated strains have been found to possess higher minimal inhibitory concentration (MIC) rates for ceftriaxone, cefotaxime and, to a lesser extent, ceftazidime. However, this resistance diminishes in the presence of $\beta$-lactamase inhibitors, such as clavulanic acid [4]. This type is considered class-A ESBL resistance, where the TEM, SHV and CTX-M type ESBL enzymes are able to hydrolyze [5].

Previous molecular characterization studies on TEM, SHV, and CTX-m genes and their derivatives, e.g. blaTEM-1 and blaSHV-12, have shown that they are epidemiologically related, and are both plasmid-borne [6]. PFGE have also been widely employed to investigate the epidemiological and genotypic relatedness of ESBLproducing bacteria [1] and to track evolving strains implicated in various geographic regions [6]. Recent studies in the Middle East have revealed a high prevalence of ESBL-producing K. pneumoniae isolates in Israel [7], and extensive spread of those carrying CTX-m-15 was reported in Lebanon, Kuwait, and Egypt [8-10]. In Saudi Arabia, CTX-M-15 producing K. pneumoniae was responsible for a neonatal intensive care unit outbreak [11].

Our goal was to characterize and determine the prevalence of genetic elements of ESBL-producing K. pneumoniae collected between 2000 and 2003 in Egypt. Isolates in this study including those from both community-acquired and nosocomial infections, were genotyped and their DNA fingerprints were compared.

\section{Methods}

\section{Bacterial isolates}

A total of $65 \mathrm{~K}$. pneumoniae were isolated from blood specimens collected as part of an infection control surveillance study carried out by the Infection Control Unit, Global Disease Detection and Response Program (GDDRP), U.S. Naval Medical Research Unit No. 3 (NAMRU-3), Cairo, Egypt, in partnership with the U.S. Centers for Disease Control and Prevention (CDC) (Table 1). Isolates were collected from 10 different Egyptian teaching hospitals distributed across seven governorates in Egypt: Cairo, Alexandria, Suez, Sohag, Dakahlia, Sharkiya, and Kafr
El-Sheikh. Microbiological isolation and biochemical identification procedures were conducted according to Clinical and Laboratory Standards Institute procedures (CLSI) [12].

\section{Antibiotic susceptibility testing and ESBL detection}

Antibiotic susceptibility was determined by the agar disk diffusion method. The following antibiotics were tested: ampicillin $(30 \mu \mathrm{g})$, imipenem $(10 \mu \mathrm{g})$, cefepime $(30 \mu \mathrm{g})$, cephalothin $(30 \mu \mathrm{g})$, ceftriaxone $(30 \mu \mathrm{g})$, cefpodoxime $(10 \mu \mathrm{g})$, ceftazidime $(30 \mu \mathrm{g})$, cefotaxime $(30 \mu \mathrm{g})$, and sulfamethoxazole $(30 \mu \mathrm{g})$ (Becton Dickinson, Sparks, MD, USA), with results interpreted using the CLSI criteria [12]. Also, minimum inhibitory concentration (MIC) was evaluated by E-test for ceftazidime, cefepime, ceftriaxone, and cephalothin (bioMérieux, France) [13]. Additionally, the detection of ESBL activity was screened by double-synergy test [14]. K. pneumoniae ATCC 700603 and E. coli ATCC 25922 were used as positive and negative controls, respectively, as recommended by CLSI guidelines for Enterobacteriaceae [12].

\section{Pulsed-field gel electrophoresis (PFGE)}

K. pneumoniae isolates were subjected to PFGE. Total DNA was extracted and digested using the Xbalrestriction enzyme following the procedures described in the PulseNet International protocols for Salmonella with minor modifications pertaining to electrophoresis running conditions in the CHEF-DR III PFGE system (BioRad, Hercules, USA): $19 \mathrm{hrs}$, with initial switch time $2.2 \mathrm{sec}$, final switch time 63.8 sec, at 6 volts, and at $120^{\circ}$ Angle [15].

\section{DNA extraction (chromosomal and plasmid)}

Twenty-four hour culture of K.pneumoniae isolates grown on MacConkey Agar were used for DNA extraction. Chromosomal and plasmid DNA extractions were performed using the Qiagen Blood Mini Kit (QIAgen Inc., Valencia CA, USA), and Wizard plus Minipreps SV DNA purification system (Promega, Madison, USA), respectively, according to the manufacturer's instructions. The quality of the extracted chromosomal and plasmid DNA was confirmed by running the extracts on $0.8 \%$ agarose gel (100 Volts, $400 \mathrm{amps}$, for $2 \mathrm{hrs})$, and by measuring the concentration of DNA by NanoDrop (Thermo Scientific, Kansas, USA).

\section{PCR screening for ESBL genes}

Both chromosomal and plasmid DNA extracts of all isolates were screened by PCR for the presence of three ESBL genes: TEM, SHV, and CTXm. Three sets of primers were designed for screening (Table 2): a core set to amplify the conserved, central region of each gene for an initial screening [16]; two sets of degenerate primers to detect the more variable upstream and downstream regions of 
Table 1 Strain information

\begin{tabular}{|c|c|c|c|c|c|c|c|c|c|c|}
\hline No & $\begin{array}{l}\text { Isolate } \\
\text { accession }\end{array}$ & Hospital site & $\begin{array}{l}\text { ESBL } \\
\text { test }\end{array}$ & $\begin{array}{l}\text { Type of } \\
\text { infection }\end{array}$ & $\begin{array}{l}\text { CTX-M } \\
\text { Plasmid }\end{array}$ & $\begin{array}{l}\text { TEM } \\
\text { Plasmid }\end{array}$ & $\begin{array}{l}\text { SHV } \\
\text { Plasmid }\end{array}$ & $\begin{array}{l}\text { CTX-M } \\
\text { Chrom }\end{array}$ & $\begin{array}{l}\text { TEM } \\
\text { Chrom }\end{array}$ & $\begin{array}{l}\text { SHV } \\
\text { Chrom }\end{array}$ \\
\hline 1 & $00-008416$ & Cairo Univ & + & Community & - & - & - & - & + & + \\
\hline 2 & $01-001425$ & Cairo Univ & + & Community & - & - & - & - & + & + \\
\hline 3 & 01-007549 & Cairo Univ & + & Nosocomial & - & - & - & - & + & + \\
\hline 4 & $01-007550$ & Cairo Univ & + & Nosocomial & - & - & - & - & + & + \\
\hline 5 & 01-007724 & Cairo Univ & + & Nosocomial & - & + & + & - & + & + \\
\hline 6 & 01-007732 & Cairo Univ & + & Nosocomial & - & - & - & - & + & + \\
\hline 7 & 01-007743 & Cairo Univ & + & Nosocomial & - & + & + & - & + & + \\
\hline 8 & 01-007949 & Cairo Univ & + & Nosocomial & - & - & - & - & + & + \\
\hline 9 & 01-007951 & Cairo Univ & + & Nosocomial & - & + & + & - & + & + \\
\hline 10 & 01-007953 & Cairo Univ & + & Nosocomial & - & - & - & - & + & + \\
\hline 11 & 01-007959 & Cairo Univ & + & Nosocomial & - & + & - & - & + & + \\
\hline 12 & 01-007961 & Cairo Univ & + & Nosocomial & - & - & - & - & + & + \\
\hline 13 & 01-007967 & Cairo Univ & + & Nosocomial & - & - & - & - & - & - \\
\hline 14 & 01-008663 & Cairo Univ & + & Nosocomial & - & - & - & - & + & + \\
\hline 15 & $01-008664$ & Cairo Univ & + & Nosocomial & - & - & - & - & + & + \\
\hline 16 & 01-008666 & Cairo Univ & + & Nosocomial & - & - & + & - & + & + \\
\hline 17 & $01-008671$ & Cairo Univ & + & Nosocomial & - & - & - & - & + & + \\
\hline 18 & 01-008672 & Cairo Univ & + & Nosocomial & - & - & - & - & + & + \\
\hline 19 & 01-008884 & Cairo Univ & + & Nosocomial & - & - & - & - & + & + \\
\hline 20 & 01-009044 & Cairo Univ & + & Nosocomial & - & - & - & - & + & + \\
\hline 21 & 01-012909 & Cairo Univ & + & Nosocomial & - & - & - & - & + & + \\
\hline 22 & 01-012910 & Cairo Univ & + & Nosocomial & - & - & - & - & + & + \\
\hline 23 & 01-012912 & Cairo Univ & + & Nosocomial & - & - & - & - & + & + \\
\hline 24 & 01-012919 & Cairo Univ & + & Nosocomial & - & - & - & - & + & + \\
\hline 25 & 01-012921 & Cairo Univ & + & Nosocomial & - & + & - & - & + & + \\
\hline 26 & 01-012925 & Cairo Univ & + & Nosocomial & - & - & - & - & + & + \\
\hline 27 & 01-013098 & Cairo Univ & + & Nosocomial & - & - & - & - & + & + \\
\hline 28 & 01-013099 & Cairo Univ & + & Nosocomial & - & - & - & - & + & + \\
\hline 29 & $01-013638$ & Cairo Univ & + & Nosocomial & - & - & - & - & + & + \\
\hline 30 & 01-013639 & Cairo Univ & + & Nosocomial & - & - & - & - & + & + \\
\hline 31 & $01-013640$ & Cairo Univ & + & Nosocomial & - & - & - & - & + & + \\
\hline 32 & 01-013906 & Cairo Univ & + & Nosocomial & - & - & + & - & + & + \\
\hline 33 & 01-015467 & Cairo Univ & + & Nosocomial & - & - & - & - & + & + \\
\hline 34 & 01-015468 & Cairo Univ & + & Nosocomial & - & - & - & - & + & + \\
\hline 35 & 01-015469 & Cairo Univ & + & Nosocomial & + & - & - & + & + & + \\
\hline 36 & 01-015470 & Cairo Univ & + & Nosocomial & + & - & - & + & + & + \\
\hline 37 & 01-015472 & Cairo Univ & + & Nosocomial & - & - & - & - & + & + \\
\hline 38 & 01-015473 & Cairo Univ & + & Nosocomial & - & - & - & - & + & + \\
\hline 39 & 01-015474 & Cairo Univ & + & Nosocomial & - & - & - & - & + & + \\
\hline 40 & 01-015475 & Cairo Univ & + & Nosocomial & - & - & - & - & + & + \\
\hline 41 & 01-015857 & Cairo Univ & + & Nosocomial & - & - & - & - & + & + \\
\hline 42 & 01-015858 & Cairo Univ & + & Nosocomial & - & - & - & - & + & + \\
\hline 43 & 01-015859 & Cairo Univ & + & Nosocomial & - & - & - & - & + & + \\
\hline
\end{tabular}


Table 1 Strain information (Continued)

\begin{tabular}{|c|c|c|c|c|c|c|c|c|c|c|}
\hline 44 & 01-015860 & Cairo Univ & + & Nosocomial & - & - & - & - & + & + \\
\hline 45 & 01-016401 & Cairo Univ & + & Nosocomial & - & - & + & - & + & + \\
\hline 46 & 01-017000 & Cairo Univ & + & Nosocomial & - & - & - & - & + & + \\
\hline 47 & 01-017852 & Cairo Univ & + & Nosocomial & - & - & - & - & + & + \\
\hline 48 & 01-017853 & Cairo Univ & + & Nosocomial & - & - & - & - & + & + \\
\hline 49 & 01-017866 & Cairo Univ & + & Nosocomial & - & - & - & - & + & + \\
\hline 50 & 01-018867 & Zagazig Univ & + & Nosocomial & - & - & + & - & + & + \\
\hline 51 & $02-000429$ & Zagazig Univ & + & Community & - & - & + & - & + & + \\
\hline 52 & 02-000569 & $\begin{array}{l}\text { Zagazig General } \\
\text { Hospital }\end{array}$ & + & Nosocomial & - & - & - & - & + & + \\
\hline 53 & 02-005285 & $\begin{array}{l}\text { Mansoura General } \\
\text { Hospital }\end{array}$ & + & Nosocomial & + & - & - & + & + & + \\
\hline 54 & 02-005864 & Sohag General Hospital & + & Nosocomial & - & - & - & - & + & + \\
\hline 55 & 02-009772 & Suez General Hospital & + & Nosocomial & - & - & - & - & + & + \\
\hline 56 & 02-009785 & Sohag General Hospital & + & Nosocomial & - & - & - & - & + & + \\
\hline 57 & 02-010707 & $\begin{array}{l}\text { Fawzi Moaz General } \\
\text { Hospital }\end{array}$ & + & Nosocomial & - & - & - & - & + & + \\
\hline 58 & 02-010718 & $\begin{array}{l}\text { Mansoura General } \\
\text { Hospital }\end{array}$ & + & Nosocomial & - & - & - & - & + & + \\
\hline 59 & 02-018404 & Suez General Hospital & + & Nosocomial & - & - & - & - & + & + \\
\hline 60 & 03-000024 & Kafr El Shiek General & + & Nosocomial & - & - & - & - & + & + \\
\hline 61 & 03-002582 & $\begin{array}{l}\text { Kafr El Shiek General } \\
\text { Hospital }\end{array}$ & + & Nosocomial & - & - & + & - & + & + \\
\hline 62 & 03-018785 & $\begin{array}{l}\text { Kafr El Shiek General } \\
\text { Hospital }\end{array}$ & + & Community & + & - & + & + & + & + \\
\hline 63 & 03-021318 & $\begin{array}{l}\text { Kafr El Shiek General } \\
\text { Hospital }\end{array}$ & + & Community & + & - & - & + & + & + \\
\hline 64 & 03-021320 & $\begin{array}{l}\text { Kafr El Shiek General } \\
\text { Hospital }\end{array}$ & + & Community & + & - & - & + & + & + \\
\hline 65 & 03-021322 & $\begin{array}{l}\text { Kafr El Shiek General } \\
\text { Hospital }\end{array}$ & + & Community & + & + & + & + & + & + \\
\hline
\end{tabular}

Isolates accessioning numbers utilized in the study are shown above: The first two digits indicate the year of collection. The last six columns indicate the presence $(+)$ or absence (-) of the genes tested on both chromosomal and plasmid. Community source of infection is distinguished in bold.

each gene for confirmation screening. PCR primers were purchased commercially (Sigma-Genosys, Taufkirchen, Germany). Five $\mu \mathrm{l}$ of the DNA template were added to complete a final PCR reaction volume of $25 \mu \mathrm{l}$ containing: $1 \times$ green reaction buffer; $3 \mathrm{mM}$ of $\mathrm{MgCl} 2$.

(Promega, Madison, USA); 0.3 pM of each primer; 2.5U of GoTaq Flexi DNA Polymerase and $0.4 \mathrm{mM}$ dNTPs. Template amplification was accomplished using the following cycle conditions: $95^{\circ} \mathrm{C}$ for 5 minutes (initial denaturation), 30 cycles of: $94^{\circ} \mathrm{C}$ for $30 \mathrm{sec}$ (denaturation), $52^{\circ} \mathrm{C}$ for $45 \mathrm{sec}$ (annealing), and $72^{\circ} \mathrm{C}$ for $45 \mathrm{sec}$ (extension), $72^{\circ} \mathrm{C}$ for $7 \mathrm{~min}$ (final extension). The annealing temperatures and times for TEM, SHV and CTXm were $52^{\circ} \mathrm{C}$ for $45 \mathrm{sec}, 55^{\circ} \mathrm{C}$ for $1 \mathrm{~min}$, and $57^{\circ} \mathrm{C}$ for $45 \mathrm{sec}$, respectively.

PCR products were visualized on Ethidium-stained 1\% agarose gels with expected product lengths of $643 \mathrm{bp}$,
714 bp and 766 bp for blaTEM, blashv, and blaCTX-m, respectively.

\section{ESBL gene sequencing}

After initial screening for the amplification of core ESBL genes on both chromosomal and plasmid, the plasmidborne TEM, SHV, or CTX-m genes were subjected to nucleic acid sequencing.

The initial PCR amplified products were purified and treated with Exo Sap-it enzyme (USB, Santa Clara CA, USA) at the ratio of $2: 1$ using $10 \mu \mathrm{l}$ of the amplicon to $5 \mu \mathrm{l}$ of the enzyme. Each mixture was incubated in a conventional thermal cycler (Applied Biosystems, CA, USA) for $15 \mathrm{~min}$ at $37^{\circ} \mathrm{C}$, followed by $15 \mathrm{~min}$ at $80^{\circ} \mathrm{C}$ according to the manufacturer's instructions. Direct sequencing of each amplicon was carried out using the Sanger dideoxynucleotide chain termination method with the ABI Prism 
Table 2 PCR and DNA primers sequencing of the three ESBL genetic markers

\begin{tabular}{|c|c|c|c|}
\hline Primer & Sequence & $\begin{array}{l}\text { Size } \\
\text { (bp) }\end{array}$ & Reference \\
\hline Core TEM F & CAGCGGTAAGATCCTTGAGA & 643 & \multirow[t]{6}{*}{ [9] } \\
\hline Core TEM R & ACTCCCCGTCGTGTAGATAA & & \\
\hline Core SHV F & GGCCGCGTAGGCATGATAGA & 714 & \\
\hline Core SHV R & CCCGGCGATTTGCTGATTC & & \\
\hline Core CTXM F & AACCGTCACGCTGTTGTTAG & 766 & \\
\hline Core CTXM R & TTGAGGCGTGGTGAAGTAAG & & \\
\hline $\begin{array}{l}\text { Upstream } \\
\text { TEM F } \\
\text { Upstream } \\
\text { TEM R }\end{array}$ & $\begin{array}{l}\text { TGAAGACGAAAGGGCCTCCTG } \\
\text { ACTCCCCGTCGTGTAGATAA }\end{array}$ & 109 & \multirow[t]{6}{*}{$\begin{array}{l}\text { Newly designed } \\
\text { primers in GDDRP } \\
\text { Molecular } \\
\text { Laboratoryfor this } \\
\text { study }\end{array}$} \\
\hline $\begin{array}{l}\text { Upstream } \\
\text { SHV F } \\
\text { Upstream } \\
\text { SHV R }\end{array}$ & $\begin{array}{l}\text { CGTTWTDTTCGCCKGTGT } \\
\text { CGAGTAGTCCACCAGATCCTG }\end{array}$ & 74 & \\
\hline $\begin{array}{l}\text { Upstream } \\
\text { XTXM-F } \\
\text { Upstream } \\
\text { CXTXM-R }\end{array}$ & $\begin{array}{l}\text { ATGGTTAAAAAATCACTG } \\
\text { ACGTTATCGCTGTACTGTA }\end{array}$ & 55 & \\
\hline $\begin{array}{l}\text { Downstream } \\
\text { TEM F } \\
\text { Downstream } \\
\text { TEM R }\end{array}$ & $\begin{array}{l}\text { CAGCGGTAAGATCCTTGAGA } \\
\text { TAATCAGTGAGGCACCTATCTC }\end{array}$ & 109 & \\
\hline $\begin{array}{l}\text { Downstream } \\
\text { SHV F } \\
\text { Downstream } \\
\text { SHV R }\end{array}$ & $\begin{array}{l}\text { GGCCGCGTAGGCATGATAGA } \\
\text { CCCGGCGATTTGCTGATTTC }\end{array}$ & 74 & \\
\hline $\begin{array}{l}\text { Downstream } \\
\text { CTXM-F } \\
\text { Downstream } \\
\text { CTXM-R }\end{array}$ & $\begin{array}{l}\text { TACAGTACAGCGATAACGTGG } \\
\text { CCGTTICCGCTATTACAAA }\end{array}$ & 55 & \\
\hline
\end{tabular}

Big Dye Terminator Cycle Sequencing Reaction Kit (Applied Biosystems, Inc., Foster City, CA, USA) on an ABI Prism 3130 Automated Sequencer. Using data collection software version 2.0, and sequencing analysis software 5.1.1.

For each sequencing reaction, $2 \mu \mathrm{l}$ purified PCR product were added to a final reaction volume of $20 \mu \mathrm{l}$ containing $1 \times$ of sequencing buffer (Applied Biosystems, CA, USA); $4 \mu$ l BigDye (Applied Biosystems, USA) reaction mix; and 1.5pM of each of the Forward and Reverse primer. The sequencing cycle was composed of two stages; stage one is denaturing at $96^{\circ} \mathrm{C}$ for $10 \mathrm{sec}$, while stage two is composed of 25 cycles of denaturing at $96^{\circ} \mathrm{C}$ for $10 \mathrm{sec}$, annealing at $50^{\circ} \mathrm{C}$ for $5 \mathrm{sec}$, and extension at $60^{\circ} \mathrm{C}$ for $4 \mathrm{~min}$

Each cycle sequence product was purified by spin column purification according to the manufacturer's instructions (Edge Biosystems, CA USA). The purified PCR product was then completely dried at $85^{\circ} \mathrm{C}$ for $30-40 \mathrm{~min}$. Fifteen $\mu \mathrm{l} \mathrm{Hi-Di}$ formamide (Applied Biosystems, CA, USA) was added to the tubes, after which the tubes were heated for $2 \mathrm{~min}$ at $95^{\circ} \mathrm{C}$, then immediately placed on ice.

\section{Data analyses}

Nucleotide sequences obtained from various isolates were assembled using the software programs BioNumerics (version 5.10) and BioEdit (version 7.0.9.0), and aligned with GenBank reference sequences using the Clustal X application within BioEdit. Translated amino acid sequences were compared with published sequences in the Lahey organization (http://www.lahey.org/studies). Phylogenetic tree was generated using the MEGA version 4 software, and dendrogram were constructed using the neighborjoining method [15]. PFGE data from the 65 isolates was analyzed using BioNumerics (version 5.10). Genetic similarities were inferred from dendrograms created using the unweighted pair-group method with average (UPGMA) analysis of the XbaI mrp-PFGE patterns using the Dice coefficient with a $1.5 \%$ tolerance for the band migration distance.

\section{Results}

\section{Antibiograms of $K$. pneumoniae isolates}

In hospitalized and community cases, $100 \%$ of the strains in this study have shown susceptibility in the presence of $\beta$-lactam inhibitor CAZ/CLA, while 98.5\% (64/ 65) were susceptible to CTX/CLA excluding one isolate (01007953) with inhibition zone diameter $\geq 5 \mathrm{~mm}$. Variable resistance patterns were seen among other antibiotics (Table 3). All $K$. pneumoniae isolates displayed resistance to ampicillin(AM), ceftazidime (CAZ), cephalothin (CE), ceftriaxone $(\mathrm{CF})$, and cefpodoxime (CPD), while the majority of isolates, 97\%, were resistant to cefotaxime (CTX). On the other hand, the isolates displayed lower rates of resistance to sulfamethoxazole (SXT), cefepime (FEP), (PM), and imipenem (IPM) (49\%, 37\%, 14\%, and $3 \%$, respectively).

\section{Molecular characterization of ESBL genes}

Amplification and sequencing primers were designed to both detect the presence of and generate templates for the accurate sequencing of the relatively large genes studied here (Table 2).

Eleven percent of isolates $(7 / 65)$ carried the CTX-m gene. The majority $(4 / 7)$ of the community isolates carried CTX-m, compared to only $5 \%(3 / 58)$ of the nosocomial isolates. Amplification of the upstream and downstream regions and sequencing of the full length PCR products (766 bp core region and $55 \mathrm{bp}$ upstream and downstream regions: 876 bp total) confirmed that the seven plasmidborne CTX-m genes were $100 \%$ identical to CTX-m-15 reported in GenBank.

Ninety-eight percent $(64 / 65)$ of the total isolates also carried the SHV core gene chromosomally. Of note, the remaining single isolate (01-007967, Table 1) was negative for the three studied genetic markers. Seventeen percent $(11 / 65)$ of isolates carried SHV on the plasmid. 
Table 3 Antibiotic resistance profile

\begin{tabular}{|c|c|c|c|c|c|c|c|c|c|c|c|c|c|c|}
\hline & \multicolumn{14}{|c|}{ Panel of antibiotic tested } \\
\hline & \multicolumn{6}{|c|}{ Disk diffusion* } & \multicolumn{4}{|c|}{ ESBL Confirmationt } & \multicolumn{4}{|l|}{ E-test‡ } \\
\hline & $\begin{array}{l}\text { Ampicillin } \\
\text { (AM) }\end{array}$ & $\begin{array}{l}\text { Imipenem } \\
\text { (IPM) }\end{array}$ & $\begin{array}{l}\text { Cefepime } \\
\text { (FEP) }\end{array}$ & $\begin{array}{l}\text { Cephalothin } \\
\text { (CF) }\end{array}$ & $\begin{array}{l}\text { Ceftriaxone } \\
\text { (CRO) }\end{array}$ & $\begin{array}{l}\text { Cefpodoxime } \\
\text { (CPD) }\end{array}$ & CAZ & $\begin{array}{l}\text { CAZI } \\
\text { CLA } \\
\text { ZONE }\end{array}$ & CTX & $\begin{array}{l}\text { CTX/ } \\
\text { CLA } \\
\text { zone }\end{array}$ & $\begin{array}{l}\text { Sulfamethoxazole } \\
\text { (SXT) }\end{array}$ & $\begin{array}{l}\text { Ceftazidime } \\
\text { (TZ) }\end{array}$ & $\begin{array}{l}\text { Cefepime } \\
\text { (PMO }\end{array}$ & $\begin{array}{l}\text { Cephalothin } \\
\text { (CE) }\end{array}$ \\
\hline $\begin{array}{l}\mathrm{N}(\%) \text { Cases with } \\
\text { resistance } \\
\text { phenotype }\end{array}$ & $65(100)$ & $1(3)$ & $24(37)$ & $65(100)$ & $61(94)$ & $65(100)$ & $\begin{array}{l}65 \\
(100)\end{array}$ & $0(0)$ & $\begin{array}{l}63 \\
(97)\end{array}$ & $1(1.5)$ & $32(49)$ & $64(98)$ & $9(14)$ & $65(100)$ \\
\hline
\end{tabular}


Four of the eleven isolates carried both the TEM and SHV genes on a plasmid, while no plasmid carriage was detected in the remaining seven isolates.

DNA sequencing analysis of whole SHV gene from 11 isolates revealed $99 \%$ similarity to SHV-12. On the nucleotide level, no similarity was found between the eleven SHV gene sequences to each other or published SHV sequences: SHV-12 (GenBank\# GU064393.1), and the closely related SHV-5 (GenBank\# HM125696.1), and SHV-2a (GenBank\# GQ407116.1). Comparison of the corresponding amino acid sequence of each gene utilizing Lahey organization study tables, demonstrated SHV12, SHV-5 and SHV-2a as the most closely related sequencing match (Table 2). Also, see Additional file 1 PDF displays SHV amino acid sequence variations of ESBL Egyptian isolates table.

\section{Macro-restriction pattern typing using Pulsed-Field Gel Electrophoresis (PFGE)}

DNA fingerprint profiling of the 65 isolates identified four major clusters (Figure 1), with strains grouped in each cluster sharing high levels of similarity (80-100\%).

PFGE identified four major clusters: cluster one grouped $32 \%$ of the samples $(n=21)$ with $54.5 \%$ similarity. Five of the eleven (45\%) plasmid-borne SHV were identified in this cluster, and their mrp were indistinguishable. Remarkably, one isolate (01-007967) did not carry any of the genes, displayed identical MRP to two isolates (01-007961, and 01-008884) carrying both TEM and SHV. Cluster two grouped the majority $41.5 \%$ of the isolates $(n=27)$, sharing $75.6 \%$ similarity and forming a broad cluster. Two plasmid-borne SHV and another two CTX-m carrying isolates were identified in this cluster and located distantly from each other. The third cluster is composed of $19 \%$ of the samples $(n=12)$, members of this cluster did not share identical MRP pattern. The fourth cluster represented the fewer number of samples $8 \%(n=5)$ where one isolate (03-021322) carried the three genetic markers for resistance.

PFGE analysis of the seven $K$. pneumoniae strains producing CTX-m-15 (Figure 2), using complete linkage, dice band-based similarity coefficient and $1.5 \%$ position tolerance, revealed 5 clusters: one pair of isolates (pattern 1) was collected from nosocomial infections at a hospital in Cairo in 2001 (01-015469 and 01-015470; > 85\% similarity). Another pair (pattern 4) were isolated in Kafr El Shiek governorate from community-acquired infections in 2003 (03-021318 and 03-021320, >80\% similarity) displayed a MRP (pattern 3) that is distantly related to another isolate detected at the same hospital (03-021322, $61.9 \%$ similarity). Two isolates each with unique pattern; one was isolated from Mansoura governorate (nosocomial, 02-005285) formed pattern 4), and another isolate from Alexandria governorate (community, 03-018785) formed pattern 5. Five distinct DNA fingerprint patterns were detected with the positive plasmid SHV isolates (Figure $2 \mathrm{~b}$ ). Interestingly, pattern 1, composed of five isolates (01007951, 01-008666, 01-013906, 01-007724, 01-016401), all were isolated from nosocomial infection collected from Cairo University. The unique MRP patterns 2 and 4, displayed by isolates 03-018785, and 03-021322, respectively, were collected from Kafr El-Shiek General Hospital but was not seen in the seven nosocomial isolates received from the same location (03-002582). Distinct patterns 3 and 5 came from community isolates collected at Zagazig University.

\section{Discussion}

\section{Antibiograms of $K$. pneumoniae isolates}

Infections caused by ESBLs producing bacteria have become an emerging global problem. Studies on Enterobacteriaceae isolates from Egypt have reported a resistance rate to third generation cephalosporins of $70 \%[17,18]$. A survey, carried out in 2001-2002 which covered medical centers in northern and southern European countries, Egypt, Lebanon, Saudi Arabia and South Africa, reported the highest incidence of extended spectrum $\beta$-lactamases (ESBLs)-producing isolates in Egypt [3]. A recent study from Egypt reported an outbreak in a neonatal intensive care unit in Cairo, Egypt, in which $80 \%$ of the isolates were $K$. pneumoniae, of which $58 \%$ were ESBL producers [19]. While the phenotypic characteristics of ESBL of enterobactericeae were widely studied in Egypt, there were very few published reports on the molecular aspect underlying mechanism of ESBL. In this study, we investigated the genetic determinants of ESBL activity in $K$. pneumoniae isolates collected from 10 different Egyptian teaching hospitals distributed across seven governorates in Egypt.

The ESBL activity of $K$. pneumoniae clinical isolates collected from both community and hospital settings is concordant with previous reports from Egypt and other countries which indicate faecal carriage of these pathogens in the community and may have important implications as a risk factor for acquiring ESBL-producing $K$. pneumoniae isolates upon hospital admission. However, the variable level of resistance of $K$. pneumoniae to other non- $\beta$-lactam antibiotics, e.g., sulfamethoxazole data, is not concordant with previous reports from Egypt, where a high level of resistance was found [20]. The difference in sulfamethoxazole resistance may be attributed to a wide dissemination of different ESBL clones of $K$. pneumoniae among different community and hospital settings.

\section{Molecular characterization of ESBL genes}

CTX-M is the most prevalent gene in ESBL-producing enterobacteriaceae worldwide [6]. Recently, CTX-M ESBLs have been reported in different studies in Egypt $[10,11,20]$. 


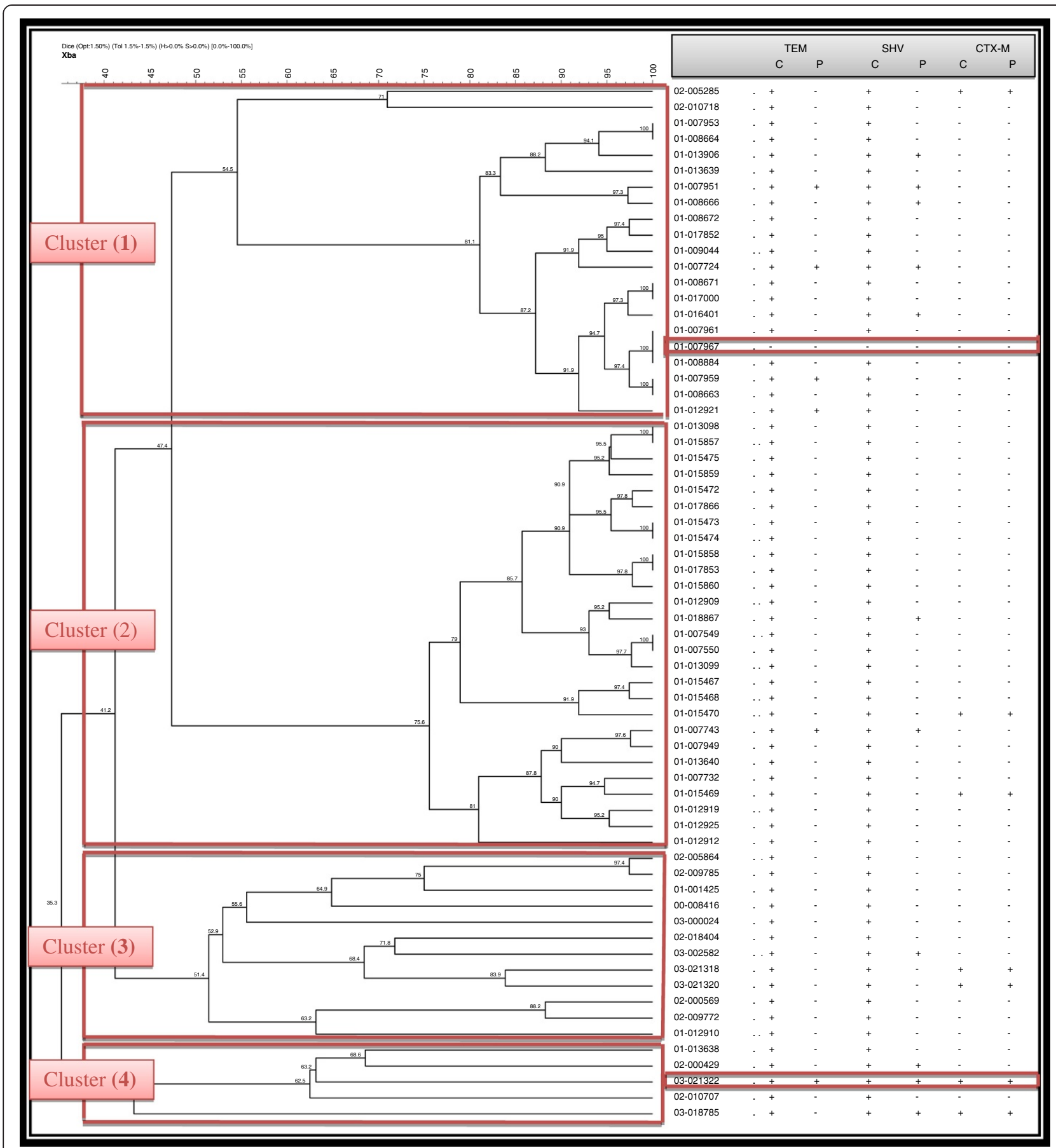

Figure 1 Phylogenetic tree of Egyptian ESBL isolates $(n=65)$ demonstrating different clusters by PFGE. C (Chromosomal), and P (Plasmid).

Previous studies have shown CTX-m-15 to be the most commonly reported ESBL type in the Middle East and North Africa $[8,20]$. In this study, however, the most common ESBL type identified in Egyptian $K$. pneumoniae isolates was SHV (98\%), compared to the relatively low prevalence of CTX-m-15 (11\%). This differs from a recent report from Egypt indicating that CTX-M-14 is the mechanism of resistance mediating the high resistance of $\beta$ lactamases $K$. pneumoniae producers to third generation Cephalosporins among resistant clinical isolates at a medical institution in Cairo, Egypt [20]. This may indicate that multiple clones of circulating $K$. pneumonia are involved in the dessimination of high ESBL resistance in both community and hospital settings. Though this study detected a relatively small number $(11 \%)$ of isolates carrying the CTX-m-15 type of ESBL, it supports our previous report 
a

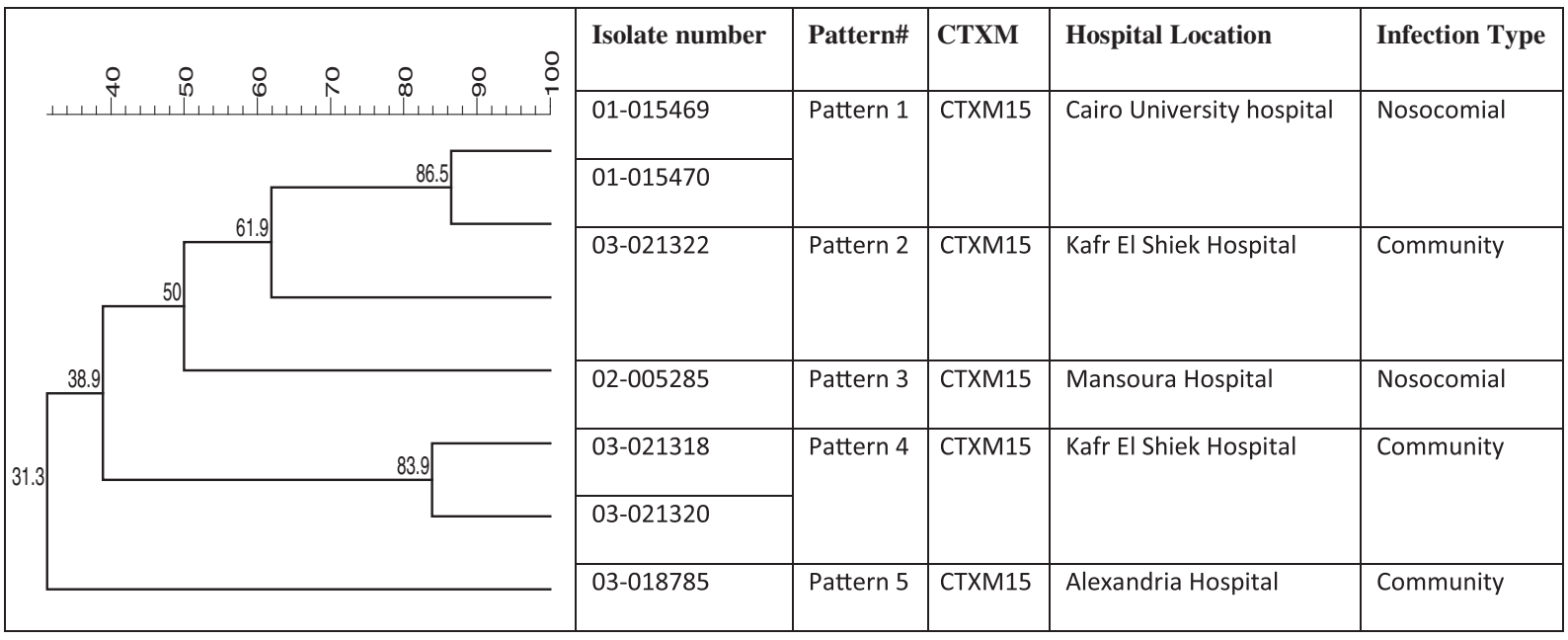

b

Dice (Opt: $1.50 \%)(\mathrm{Tol} 1.5 \%-1.5 \%)$

$(\mathrm{H}>0.0 \% \mathrm{~S}>0.0 \%) \mathrm{Xba}-1$

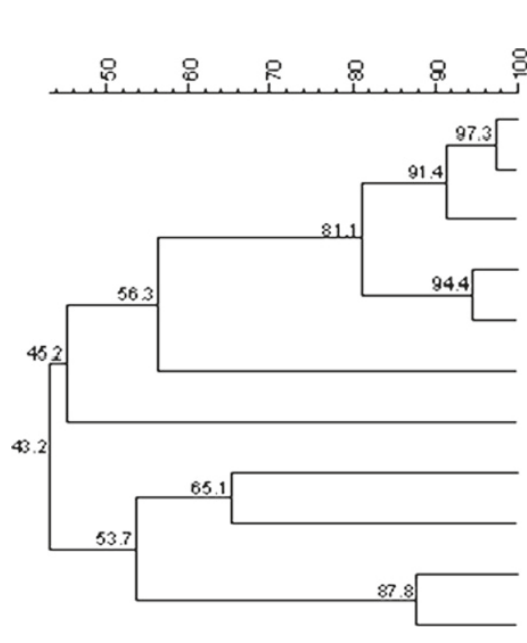

\begin{tabular}{|c|c|c|c|c|}
\hline Isolate number & Pattern & Shv type & Hospital Location & Infection Type \\
\hline 01-007951 & \multirow[t]{5}{*}{ Pattern 1} & bla $_{\mathrm{SHV}-12}$ Variant & Cairo Univ & Nosocomial \\
\hline $01-008666$ & & bla $_{\mathrm{SHV}-12}$ Variant & Cairo Univ & Nosocomial \\
\hline 01-013906 & & bla $_{S H V-5,2 a}$ Variant & Cairo Univ & Nosocomial \\
\hline 01-007724 & & bla $_{\mathrm{SHV}-12}$ Variant & Cairo Univ & Nosocomial \\
\hline 01-016401 & & bla $_{\text {SHV-5, 2a }}$ Variant & Cairo Univ & Nosocomial \\
\hline 03-018785 & Pattern 2 & bla $a_{S H V-5,2 a}$ Variant & Kafr El Shiek Hospital & Community \\
\hline $02-000429$ & Pattern 3 & bla $_{\mathrm{SHV}-12}$ Variant & Zagazig Univ & Community \\
\hline $03-002582$ & \multirow[t]{2}{*}{ Pattern 4} & bla $_{\mathrm{SHV}-12}$ Variant & Kafr El Shiek Hospital & Nosocomial \\
\hline 03-021322 & & bla $_{\mathrm{SHV}-12}$ Variant & Kafr El Shiek Hospital & Community \\
\hline 01-007743 & \multirow[t]{2}{*}{ Pattern 5} & $100 \%$ bla $_{\text {SHV }-12}$ & Cairo Univ & Nosocomial \\
\hline 01-018867 & & bla $_{\text {SHV-12 }}$ Variant & Zagazig Univ & Nosocomial \\
\hline
\end{tabular}

Figure 2 PFGE Analysis. 2a. PFGE analysis of the seven CTXM-15 K. pneumoniae producers strains. The dendrogram was constructed with dice coefficient, complete linkage, and 1.5\% position tolerance. The degree of relatedness between K. pneumoniae isolates and those from GenBank is shown on the branches. $\mathbf{2 b}$. PFGE analysis of the 11 K. pneumoniae strains producing SHV-12, SHV5 and SHV-2a. The dendrogram was constructed with dice coefficient, complete linkage, and $1.5 \%$ position tolerance. The degree of relatedness among $K$. pneumoniae isolates and those from GenBank is shown on the branches.

from Egypt indicating the higher prevalence of CTX-m ESBL-producers in E. coli than in K. pneumoniae [10]. Nevertheless, resistance has been maintained and is spreading regardless of the use of extended-spectrum cephalosporins in metropolitan areas of Egypt [21]. The evidence of possible outbreaks involving CTX-m-15 warrants the implementation of strict hospital infection control policies, including the review of current therapeutic modalities, control of the use of non-prescribed antibiotics, and continuous monitoring of antibiotic sensitivity profiles of $K$. pneumoniae isolates.

As TEM is the primary genetic element implicated in the evolution of ESBL resistance mechanisms [22], we tested for this $\beta$-lactamase type. Ninety eight percent 
$(64 / 65)$ of current isolates carried the TEM core gene on the chromosome, while only nine percent (6/65) carried the gene on a plasmid (Table 1). Amplification and DNA sequencing of the six plasmid-borne genes revealed $100 \%$ identity to the TEM-1 gene reported in GenBank (EU979561.1). Even though TEM 1 is not considered an extended-spectrum $\beta$-lactamase, it may contribute to this extended spectrum of resistance in concert with other $\beta$ lactamases [4].

It is worth mentioning that isolate 01-007967 did not carry TEM, SHV, or CTX-M genes either on the chromosome or on a plasmid. It is likely that this isolate carries one or more $\beta$-lactamase genes not tested in this study. It is also possible that any number of the other isolates carried additional undetected $\beta$-lactamase genes that conferred the phenotypic high antimicrobial resistance seen.

Comparison of the corresponding amino acid sequence of the $11 \mathrm{SHV}$ positive isolates demonstrated the predominance of SHV-12, while SHV-5 and SHV-2a was the most closely related sequencing match in the remaining isolates. SHV-12 is thought to have evolved from SHV-2a, and SHV-5 from SHV-2 [8]. In comparison, SHV-12 contains only one amino acid (AA) difference at position 31: SHV12 possesses a Glutamine, while both SHV-2a and SHV-5 possess a Leucine. Upon blasting the nucleic acid sequence of the eleven plasmid-borne SHV genes against GenBank entries, our collection displayed a matching similarity value of $99 \%$ to SHV-12 and the closely related SHV-2a and SHV-5 genes [23]. Our phylogenetic tree analysis illustrated the relatedness among the $K$. pneumoniae isolates and SHV-12 (GU064393.1, K. pneumoniae strain HB $52 \beta$-lactamase blaSHV-12 isolated in Brazil), SHV-2a (GQ407116.1, K. pneumoniae strain HB $34 \beta$-lactamase blaSHV-2a isolated in Brazil), and SHV-5 (HM125696.1, K. pneumoniae strain S-486 $\beta$-lactamase SHV-5 isolated in Russia) GeneBank isolates, enabling to conclude that these genes are globally circulated.

Among the SHV carrying isolates, polymorphisms were seen at position $31(\mathrm{Q}$ or $\mathrm{L})$, position 6 ( $\mathrm{R}$ or $\mathrm{L}$ ), positions 234-235 (SK, GE or SE), and positions 3-4 (YI or FV) of the enzyme. Of particular interest, four variants possessed three AA differences at positions 3, 4 and 6 (FV-R versus YI-L). Remarkably, some significant changes to the functionality of the enzyme were spotted due to the amino acid substitutions. Occurrence of T17G (Leu to Arg, position 6 of the enzyme) in four isolates, where the aliphatic side chain very hydrophobic leucine was substituted with the basic side chain hydrophilic arginine, indicates, higher potential in utility modification. Similarly, the substitutions of the hydroxyl and basic side chain in serine and lysine with aliphatic and an acidic amide side chain in glycine and glutamate in three isolates with different arrangement, suggest functional alteration at positions 234 and 235 on the enzyme, respectively. A fifth SHV variant (01-013906) possessed these three AA differences at positions 3, 4 and 6 and an additional two differences at positions 234 and 235 (GE versus SK).

\section{Community vs. nosocomial}

Although the number of community isolates was quite small (7 versus 58) compared to the nosocomial isolates, a higher ratio of community isolates carried plasmidmediated ESBL genes. Fifty seven percent of the community isolates carried CTX-m gene versus 5\% nosocomial isolates which had the gene. Moreover, $\mathrm{SHV}$ has been detected in $43 \%$ of the community isolates, versus $13 \%$ of the nosocomial isolates. The significant presence of plasmid-mediated genes among the community isolates indicates higher potential of exchanging virulence factors in the community than the relative possibility in hospitals. In fact, nosocomial outbreaks occur due to dominating closely related strains that are being transmitted among hospitalized patients within same hospital wards or units. Accordingly, the probability for wide genetic variations is narrowed in hospital infections, due to the absence of selective environmental pressures by specific genetic elements, unlike the case in community infections where the unconstrained use of antibiotics is driving the continual transfer of antibiotic resistance genes. Thus, suggests applying restrictions on antibiotic usage, and the necessity for advances and finding alternatives for currently available treatment options.

\section{Macro-restriction pattern typing using Pulsed-Field Gel Electrophoresis (PFGE)}

PFGE analysis did not demonstrate an association between genetic background and any given ESBL phenotype. Furthermore, as the macro-restriction pattern of SHV displays different patterns among the 11 blashv positive isolates, it suggests possible carriage of the gene on different antibiotic resistance plasmids [24]. Such a variety of plasmids gives endless options to exchange virulence factors like antibiotic resistance, and hence a high potential of evolution.

In conclusion, this study demonstrates that CTX-m-15, and SHV-12 genes are associated with an ESBL resistance phenotype in K. pneumoniae in Egypt, without displaying a coherent related pattern of a DNA fingerprint profile. This suggests that the strains are heterogeneous, and their dissemination, whether in the community or at a hospital, was driven by strains of different genetic background that suggests great possibilities of variation and spread. Although one isolate (01-007967) conferred high ESBL resistance phenotype, it failed to identify any of the three genes reported in this study. Further investigation is required to determine the prevalence of such isolates in the 
community and hospital settings on a large scale and to identify other possible ESBL resistance mechanisms.

It is recommended that future work be done to determine the plasmid types that carried the plasmid-mediated genes mentioned, and apply the multilocus sequence typing (MLST) [13] to characterize the allelic profile of blaSHV K. pneumoniae isolates circulating in Egypt.

One limitation of the study is that we did not test for the horizontal movement of genes by performing a conjugation experiment to examine the self-transferable capability [25].

\section{Conclusions}

This is the first study demonstrated the occurrence of SHV-12, and SHV-5 and SHV-2a variants in Egypt. SHV-12 is associated with high-level resistance to Ceftazidime, and one of the common class A ESBLs types spreading in K. pneumonia.

\section{Additional file}

Additional file 1: Table S1. SHV amino acid sequence variations of

ESBL Egyptian isolates.

\section{Competing interests}

The authors declared that they have no competing interest.

\section{Authors' contributions}

EAN carried out the molecular genetic studies, participated in the sequence alignment and drafted the manuscript. EAN, SFA participated in the sequence alignment. EAN, SFA, GP, BH, EV participated in the design of the study and performed the statistical analysis. EAN, SFA, GP, BH, EV conceived of the study, and participated in its design and coordination and helped to draft the manuscript. All authors read and approved the final manuscript.

\section{Acknowledgements}

The authors are indebted to Dr John Klena for his precious advice and help throughout the study. The technical support of Mr. M. Abdel Maksoud, and the review of Dr. Mayar Said is highly appreciated. Esmeralda Valiente thanks for funding from Marie Curie Intraeuropean Fellowship. Copyright Statement: Enas Newire is an employee of the U.S. Government. This work was prepared as part of her official duties. Title 17 U.S.C. \$105 provides that 'Copyright protection under this title is not available for any work of the United States Government.' Title 17 U.S.C. \$101 defines a U.S. Government work as a work prepared by a military service member or employee of the U.S. Government as part of that person's official duties.

\section{Author details}

${ }^{1}$ Global Disease Detection and Response Program, U.S. Naval Medical Research Unit No. 3 (NAMRU-3), Abbassia, Cairo, Egypt. ²Department of Pathogen Molecular Biology, London School of Hygiene and Tropical Medicine, Keppel Street, London, UK.

Received: 11 April 2013 Accepted: 30 June 2013

Published: 18 July 2013

\section{References}

1. Podschun R, Ullmann U: Klebsiella spp. as Nosocomial Pathogens: Epidemiology, Taxonomy, Typing Methods, and Pathogenicity Factors. Clin Microbiol Rev 1998, 11:589-603.

2. Haeggman S: Evolution of Beta-Lactam resistance in Klebsiella pneumoniae. Stockholm, Sweden: Karolinska Institute. Swedish Institute of Infectious Disease Control; 2010. http://diss.kib.ki.se/2010/978-91-7409-938-6/thesis.pdf.
3. Bouchillon SK, Johnson BM, Hoban DJ, Johnson JL, Dowzicky MJ, Wu DH Visalli MA, Bradford PA: Determining incidence of extended spectrum beta-lactamase producing Enterobacteriaceae, vancomycin-resistant Enterococcus faecium and methicillin-resistant Staphylococcus aureus in 38 centres from 17 countries: the PEARLS study 2001-2002. Int J Antimicrob Agents 2004, 24:119-124.

4. Paterson DL, David L, Bonomo RA: Extended-Spectrum $\beta$-Lactamases: a clinical update. Clin Microbiol Rev 2005, 18:657-686.

5. Pitout JD, Thomson KS, Hanson ND, Ehrhardt AF, Moland ES, Sanders C: $\beta$-Lactamases Responsible for Resistance to Expanded-Spectrum Cephalosporins in Klebsiella pneumoniae, Escherichia coli, and Proteus mirabilis isolates recovered in South Africa. J Antimicrob Agents Chemother 1998, 42:1350-1354

6. Bagattini M, Crivaro V, Di Popolo A, Gentile F, Scarcella A, Triassi M, Villari P, Zarrilli R: Molecular epidemiology of extended-spectrum b-lactamase-producing Klebsiella pneumoniae in a neonatal intensive care unit. J Antimicrob Chemother 2006, 57:979-982.

7. Adler A, Paikin S, Sterlin Y, Glick J, Edgar R, Aronov R, Schwaber MJ, Carmeli Y: A Swordless Knight: the epidemiology and molecular characteristics of the blaKPC-negative sequence-type 258 Klebsiella pneumoniae clone. J Clin Microbiol 2012, 10:3180-3185.

8. Moubareck C, Daoud Z, Hakimé NI, Hamzé M, Mangeney N, Matta H, Mokhbat JE, Rohban R, Sarkis DK, Doucet-Populaire F: Countrywide Spread of Community and Hospital-Acquired Extended-Spectrum $\beta$-Lactamase (CTX-M-15)-Producing Enterobacteriaceae in Lebanon. J Clin Microbiol 2005, 43:3309-3313.

9. Ensor VM, Jamal W, Rotimi VO, Evans JT, Hawkey PM: Predominance of CTX-M-15 extended spectrum beta-lactamases in diverse Escherichia coli and Klebsiella pneumoniae from hospital and community patients in Kuwait. Int J Antimicrob Agents 2009, 33:487-489.

10. Fam N, Leflon-Guibout V, Fouad S, Aboul-Fadl L, Marcon E, Desouky D, El-Defrawy I, Abou-Aitta A, Klena J, Nicolas-Chanoine MH: CTX-M-15-producing Escherichia coli clinical isolates in Cairo (Egypt), including isolates of clonal complex ST10 and clones ST131, ST73, and ST405 in both community and hospital settings. Microb Drug Resist 2011, 17:67-73.

11. Al-Agamy M, Shibl A, Tawfik A, Elbannai AR: Klebsiella pneumoniae Producing CTX-M-15 Genes from Neonatal Intensive Care Unit in Saudi Arabia. Res J Microbiol 2009, 4:278-285.

12. Clinical and Laboratory Standards Institute: Performance Standards for Antimicrobial Susceptibility Testing; Twenty First informational Supplement, CLSI document M 100-S21. Wayne, PA; USA: Clin and Lab standards Institute; 2011.

13. Tóth Á, Damjanova I, Puskás E, Jánvári L, Farkas M, Dobák A, Böröcz K, Pászti J: Emergence of a colistin-resistant KPC-2-producing Klebsiella pneumoniae ST258 clone in Hungary. Eur J Clin Microbiol Infect Dis 2010, 29:765-769.

14. Jarlier V, Nicolas MH, Fournier G, Philippon A: Extended broad-spectrum $\beta$-lactamases conferring transferable resistance to newer ß-lactam agents in Enterobacteriaceae: hospital prevalence and susceptibility patterns. Rev Infect Dis 1988, 10:867-878.

15. PulseNet USA: One-Day (24-28h) Standardized Laboratory Protocol for Molecular Subtyping of Escherichia coli 0157:H7, Salmonella serotypes, and Shigella sonnei by Pulsed Field Gel Electrophoresis (PFGE). Pulse Net Internat. 2009. http://www. pulsenetinternational.org/assets/PulseNet/uploads/pfge/PNL05_Ec-SalShigPFGEprotocol.pdf.

16. Chen S, Zhao S, White D, Schroeder CM, Lu R, Yang H, McDermott PF, Ayers S, Meng J: Characterization of Multiple-Antimicrobial-Resistant Salmonella Serovars Isolated from Retail Meats. Appl Envir 2004, 70:1-7.

17. El-Kholy A, Baseem H, Procop G, Hall G, Longworth D: Antimicrobial resistance in Cairo, Egypt 1999-2000: a survey of five hospitals. J Antimicrob Chemother 2003, 51:625-630.

18. Borg MA, Scicluna E, De Kraker M, Sande-Bruinsma N, Tiemersma E, Gur D, Ben Redjeb S, Rasslan O, Elnassar Z, Benbachir M: Antibiotic resistance in the southeastern Mediterranean - preliminary results from the ARMed project. Eur Surveillance 2006, 7:164-167.

19. Moore KL, Kainer MA, Badrawi N, Afifi S, Wasfy M, Bashir M, Jarvis WR, Graham TW, El-Kholy A, Gipson R, Jernigan DB, Mahoney F: Neonatal sepsis in Egypt associated with bacterial contamination of glucose-containing intravenous fluids. Pediatrics J Infect Dis 2005, 24:590-594.

20. Khalaf N, Eletreby G, Hanson M, Nancy D: Characterization of CTX-M ESBLs in Enterobacter cloacae, Escherichia coli and Klebsiella pneumoniae clinical isolates from Cairo. Egypt BioMed Centr Infect Dis 2009, 9:84. 
21. Al-agamy M, Ashour M, Wiegand I: First description of CTX-M $\beta$-lactamase-producing clinical Escherichia coli isolates from Egypt. Int J Antimicrobial Agents 2006, 27:545-548.

22. Carattoli, Alessandra: Plasmid-Mediated Antimicrobial Resistance in Salmonella enterica. Current Issues Mol Biol 2003, 5:113-122. http://www. horizonpress.com/cimb/v/v5/10.pdf.

23. Ford PJ, Avison MB: Evolutionary mapping of the SHV beta-lactamase and evidence for two separate IS26-dependent blaSHV mobilization events from the Klebsiella pneumoniae chromosome. J Antimicrob Chemother 2004, 54:69-75.

24. Chanawong A, M'Zali FH, Heritage J, et al: SHV-12, SHV-5, SHV-2a and VEB-1 extended-spectrum $\beta$-lactamases in Gram-negative bacteria isolated in a university hospital in Thailand. J Antimicrob Chemother 2001, 48:839-852.

25. Corkill EJ, Anson JJ, Anthony Hart C: High prevalence of the plasmid-mediated quinolone resistance determinant qnrA in multidrug-resistant Enterobacteriaceae from blood cultures in Liverpool, UK. J Antimicrob Chemother 2005, 56:1115-1117.

doi:10.1186/1476-0711-12-16

Cite this article as: Newire et al: Detection of new SHV-12, SHV-5 and

SHV-2a variants of extended spectrum Beta-lactamase

in Klebsiella pneumoniae in Egypt. Annals of Clinical Microbiology and

Antimicrobials 2013 12:16.

\section{Submit your next manuscript to BioMed Central and take full advantage of:}

- Convenient online submission

- Thorough peer review

- No space constraints or color figure charges

- Immediate publication on acceptance

- Inclusion in PubMed, CAS, Scopus and Google Scholar

- Research which is freely available for redistribution 